\begin{tabular}{|l|l|}
\hline & \\
& ESCOLA DE COMUNICAÇÃO,
\end{tabular}

JORNALISMO

\title{
Estudos de gênero na pesquisa em jornalismo no Brasil: a relação tênue continua
}

\author{
Gender studies in journalism research in Brazil: the tenuous relationship continues \\ Estudios de género en la investigación periodística en Brasil: la tenue relación continúa
}

\section{Monica Martinez ${ }^{1}$ orcid.org/0000-0003-1518-8379 martinez.monica@uol.com.br}

\section{Claudia Lago ${ }^{2}$ \\ orcid.org/0000-0002-1207-2568 claudia.lagoo7@usp.br}

\section{Vanessa Heidemann ${ }^{1}$} orcid.org/0000-0002-4775-1827 vanessa_heidemann@hotmail. com

Recebido em: 5 out. 2021. Aprovado em: 12 jan. 2022 Publicado em: 7 mar. 2022.
Resumo: Em pesquisa anterior na base de dados da Associação Brasileira de Pesquisadores em Jornalismo (SBPJOR) (MARTINEZ; LAGO; LAGO, 2016), que cobre o período 2010-2014, apontamos para um possivel boom das pesquisas relacionando jornalismo aos estudos de gênero. Neste presente levantamento, realizado na base de dados dos grupos de pesquisa de jornalismo da Intercom nos últimos cinco anos (2016-2020), comprovamos este aumento quantitativo dos trabalhos. Apesar do incremento, permanece uma relação tênue na questão da integração teórica dos dois campos de estudo, na medida em que boa parte dos trabalhos apresentados não incorpora de forma consistente a vasta perspectiva dos Estudos de Gênero, mantendo um tipo de pesquisa com caráter descritivo (PERUZZO, 2018), não aprofundando a possibilidade de utilização do conceito de gênero enquanto uma categoria de análise (SCOTT, 1995) operacional para entender o campo do jornalismo.

Palavras-chave: Estudos de gênero. Pesquisa em jornalismo. Intercom.

Abstract: Results of a previous study in the SBPJOR (Brazilian Association of Journalism Researchers) database (MARTINEZ; LAGO; LAGO, 2016), covering the period 2010-2014, pointed to a possible boom in research relating journalism to gender studies. In this study, carried out in the database of Intercom's journalism research groups in the last five years (2016-2020), we prove the quantitative increase in the work. Despite the increase, there remains a tenuous relationship in the issue of theoretical integration of the two fields, as most of the studies are descriptive (PERUZZO, 2018) and do not use the concept of gender as an operational category of analysis (SCOTT, 1995) to understand the field of journalism. Keywords: Gender studies. Journalism research. Intercom.

Resumen: En una encuesta previa en la base de datos SBPJOR (Asociación Brasileña de Investigadores de Periodismo) (MARTINEZ; LAGO; LAGO, 2016), que cubría el período 2010-2014, apuntamos a un posible auge de las investigaciones que relacionan el periodismo con los estudios de género. En esta encuesta, realizada en la base de datos de los grupos de investigación en periodismo de Intercom en los últimos cinco años (2016-2020), comprobamos este incremento cuantitativo en el trabajo. A pesar del incremento, se mantiene una relación tenue en el tema de la integración teórica de los dos campos de estudio, ya que gran parte del trabajo presentado no incorpora consistentemente la perspectiva amplia de los Estudios de Género, manteniendo un tipo de investigación con carácter descriptivo (PERUZZO, 2018), sin profundizar en la posibilidad de utilizar el concepto de género como categoría operativa de análisis (SCOTT, 1995) para comprender el campo del periodismo.

Palabras clave: Estudios de género. Investigación periodistica. Intercom. 


\section{Introdução}

Em texto clássico sobre o emprego do conceito de gênero nas pesquisas históricas, Joan Scott (1995) apontava para a importância de este ser incorporado não apenas como mais um dos conceitos possiveis na área, mas como uma "categoria de análise", ou seja, como um orientador do olhar que efetivamente mudasse a práxis do narrar a história. Defendia a autora que a pesquisa histórica, em qualquer subcampo, deveria ser atravessada pela perspectiva do gênero (que se relacionaria também com as categorias de raça e classe). Isso levaria à construção de uma história que incluisse a narrativa de oprimidas(os), "uma análise do sentido e da natureza de sua opressão" e uma "compreensão de que as desigualdades de poder estão organizadas ao longo de, no mínimo três eixos". No texto a autora ainda aponta para as dificuldades de assunção desta perspectiva, na medida em que o conceito só se tornava operativo em relação a um tipo específico de pesquisas, ou:

Em outros termos, esse uso do gênero só se refere aos domínios - tanto estruturais quanto ideológicos - que implicam em relações entre os sexos. Porque na aparência a guerra, a diplomacia e a alta política não tem explicitamente nada a ver com essas relações (SCOTT, 1995, p. 76)

Desta forma, a incorporação do conceito de gênero como "categoria de análise" implicava em um desafio teórico que desse conta de pensar o atravessamento de gênero nas relações sociais humanas e no dar sentido à organização e à percepção do conhecimento histórico (SCOTT,1995. p. 73).

A categoria gênero, sob essa perspectiva, não foi plenamente incorporada ao campo da história. No campo da comunicação, que passa a se relacionar com o conceito de gênero mais tardiamente, a relação com o gênero enquanto categoria de análise é ainda mais incipiente - em que pese a centralidade desse campo na relação com tão poderosas tecnologias de gênero (LAURENTIS, 1994).

Esta relação bastante tênue do conceito de gênero com as pesquisas no campo da comunicação tem sido apontada por mapeamentos como o de Escosteguy e Messa (2006), que em sua pesquisa identificaram 65 trabalhos no conjunto das teses e dissertações dos programas de pós-graduação na área afeitas à temática produzidas de 1992 a 2002. As autoras separam os períodos e, de 2000 a 2002, indicam a preponderância de trabalhos que se organizaram dentro da chave de "muitas representações do feminino" (ESCOSTEGUY; MESSA, 2006, p. 74). Em levantamento de teses e dissertações posterior, com janela temporal de 1972 a 2015. Tainan Pauli Tomazetti (2019) indica que, das 13.265 pesquisas produzidas na época em comunicação, 316 se relacionaram ao campo dos estudos de gênero - o que daria pouco mais de $2 \%$. Mapeando as linhas de força teóricas de apropriação desses estudos, o trabalho aponta duas vertentes principais: a) pesquisas que se referem/se apoiam nos estudos feministas, com reflexões sobre especialmente as representações do universo feminino (com 240 trabalhos); e b) estudos ancorados em uma perspectiva LGBTQIAP+, voltados à produção das diferenças de gênero e constituição das sexualidades $(62$ trabalhos). Também pensando em termos de tendências de pesquisas por periodos, o mapeamento indica a revitalização das pesquisas sobre gênero a partir de 2010, especialmente trabalhos empíricos, com pouca ancoragem no campo dos estudos de gênero. Essa perspectiva já era apontada anteriormente (TOMAZETTI; CORUJA, 2017), quando autores, circunscrevendo o olhar às pesquisas de recepção e consumo midiático, indicavam a lacuna teórica dessas pesquisas e a tendência a pensar gênero como constituinte de amostras demográficas, ou seja, apenas como um substituto para estudos sobre mulheres e/ ou homens - em uma perspectiva contrária ao que se pretendeu com o emprego do conceito.

Em trabalho mais recente, também operando a partir de uma chave histórica, Escosteguy (2019) indica o aparecimento recente de pesquisas que se voltam a analisar a militância feminista e LGBTQIAP+ na internet, o que indicaria uma ampliação não apenas dos objetos de análise, mas também um aumento qualitativo na produção das pes- 
quisas sobre gênero no campo da comunicação. Apesar desses estudos indicarem uma ampliação do escopo das análises a autora, no entanto, adverte para a possibilidade de retrocesso em função do "recrudescimento conservador" (2019, p. 19) no país.

Pensando especificamente em pesquisas que tomam como campo o jornalismo (MARTINEZ; LAGO; LAGO, 2016), havíamos postulado que a relação com os estudos de gênero tendia a um crescimento, mas que este era marcado por uma relação tênue, já que acabavam seguindo uma linha descritiva, com o conceito não como uma categoria de análise, aos moldes de Scott (1995), mas como um indicador pouco explorado e não mobilizado para ajudar a pensar as complexas relações entre as construções hierárquicas ancoradas na "diferença percebida entre os sexos" (SCOTT, 1995, p. 86) e os dispositivos midiáticos, que fazem parte do conjunto de "doutrinas" (SCOTT, 1995, p. 86) que constroem e legitimam estas diferenciações e, portanto, os sistemas sociais desiguais que delas se originam. ${ }^{3}$

Para ampliar esse olhar, o presente estudo emprega uma base de dados maior, a saber a dos trabalhos apresentados nos congressos da Intercom nos últimos cinco anos (2016 a 2020). Neste novo corpus analisado, nota-se igualmente o crescimento em termos numéricos, como indicado no estudo anterior - com a diferença de observar-se uma desaceleração nas variações anuais observadas. Já as temáticas são extremamente variadas. Contudo, as apropriações teóricas possiveis ainda são limitadas, como veremos a seguir.

\section{Abordagem metodológica}

O corpus que constitui esta pesquisa foi rastreado por meio do Portal de Livre Acesso à Produção em Ciências da Comunicação da Intercom - Portcom (http://www.portcom.intercom.org.br/) no dia 21 de maio de 2018 (MARTINEZ; HEIDEMANN, 2018) e, posteriormente, foi atualizado em relação ao ano de 2020 no dia 9 de maio de 2021. Foi utilizada a palavra gênero no campo de busca e selecionada a categoria trabalhos em eventos com o propósito de rastrear as produções sobre as relações de gênero no âmbito do jornalismo. A pesquisa retornou um total de 412 trabalhos, dos quais os relacionados a gêneros jornalísti$\cos ^{4}$ e apresentados em outras áreas não foram considerados. Destes, foram selecionados 120 trabalhos apresentados nos últimos cinco anos (2016 a 2020), que se referiam à pesquisa em jornalismo, apresentados nos grupos de pesquisa relativos a esse campo e no Intercom Jr.

Esses trabalhos foram dispostos em tabela contendo nome, titulação e instituição de autores(as), título, ano de apresentação, resumo e GP no qual foram apresentados.

Devido ao volume de dados coletados, optou-se por estabelecer categorias, com base na proposta de Bardin (2011) a partir apenas dos metadados citados, não se lendo o texto em sua integralidade.

A primeira observação que essa leitura aponta é a distribuição dos trabalhos no tempo, conforme gráfico abaixo.

Para se ter uma ideia da proporção, segundo dados da Intercom (NASCIMENTO, 2021), em 2020 o total dos trabalhos aceitos nos cinco Grupos de Pesquisa de Jornalismo da Intercom (Gêneros Jornalísticos, História do Jornalismo, Jornalismo Impresso, Telejornalismo e Teorias do Jornalismo) foi de 113. No mesmo ano, o Intercom Júnior Jornalismo contou com 165 trabalhos aceitos. Em 2019, foram 97 trabalhos aceitos, sendo 61 no Intercom Júnior. Em 2018, 120 e 69, respec-

\footnotetext{
3 Para Scott, "(1) o gênero é um elemento constitutivo das relações sociais baseadas nas diferenças percebidas entre os sexos e (2) o gênero é uma forma primária de dar significado às relações de poder. Neste sentido, "implica quatro elementos inter-relacionados" (SCOTT, 1995, p. 86), quais sejam: símbolos culturalmente disponíveis, conceitos normativos que determinam o significado destes simbolos, as doutrinas religiosas, políticas, educativas, científicas, jurídicas (e aqui colocamos os discursos midiáticos), "que tomam a forma típica de uma oposição binária fixa, que afirma de maneira categórica e inequívoca o significado do homem e da mulher, do masculino e do feminino". Também compõe o conceito (enquanto categoria de análise histórica) a necessidade de uma concepção de política e uma referência às instituições e à organização social, além da identidade subjetiva.

4 Destaca-se aqui que, tradicionalmente no campo de estudos em jornalismo no Brasil, a palavra gênero refere-se ao formato da peça jornalistica. À guisa de exemplo, Marques de Mello, pioneiro nestes estudos, propõe como legítimos os gêneros informativo, opinativo, interpretativo, utilitário e diversional, onde insere o Jornalismo Literário, por exemplo (ver MELO; LAURINDO; ASSIS, 2012, p. 21).
} 
tivamente. Em 2017, 170 e 134, respectivamente. Por fim, em 2016, foram aceitos 185 e 113. Abaixo, gráfico com a distribuição dos trabalhos no tempo,

Gráfico 1 - Distribuição de trabalhos no tempo em comparação com o total dos trabalhos nos GPs e Intercom Jr.

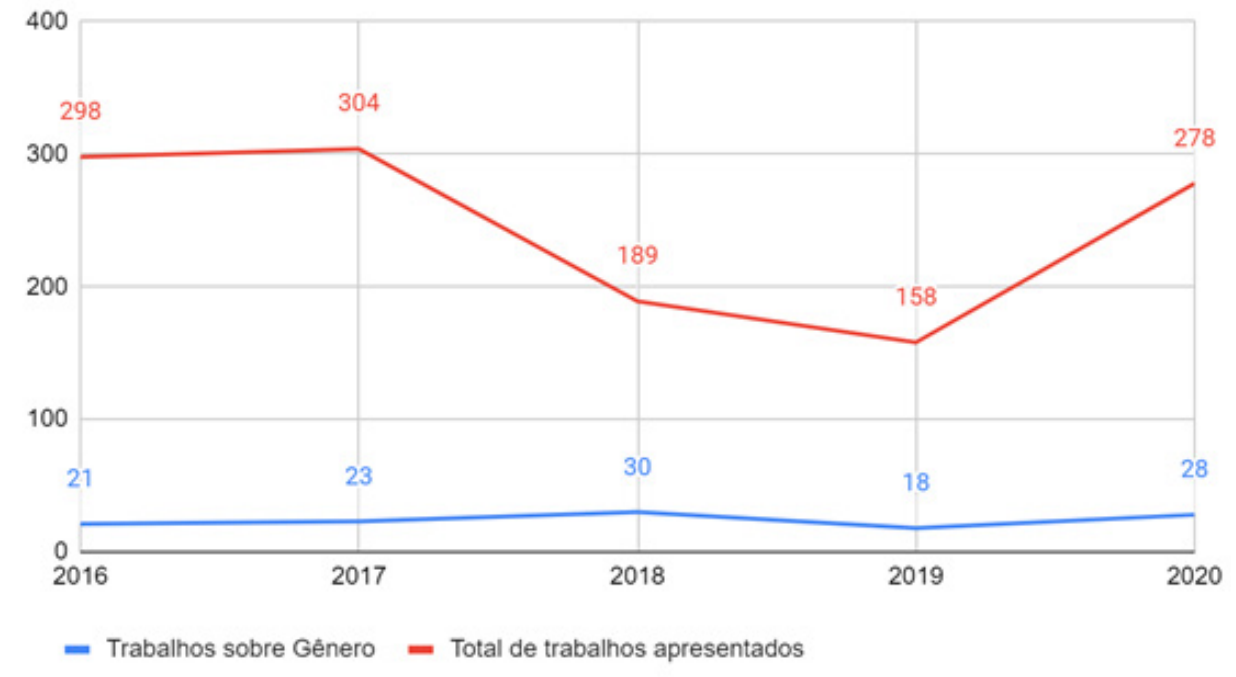

Fonte: Os autores (2021)

Finalmente, os textos foram separados em seis categorias: 1) Representações do feminino; 2) Representações LGBTQIAP+; 3) Relações de gênero; 4) Mulheres e mercado de trabalho; 5) Jornalismo de mulheres/feminista; 6) Gênero como conceito. As categorias estão descritas na próxima seção.

\section{Resultados e discussão}

O maior volume de trabalhos a partir da menção ao conceito de gênero se deu compreensivelmen te em 2018, quanto a temática Gênero foi central para o Congresso da Intercom. Não obstante, permaneceu alta em 2020 e tem estado perto dos vinte trabalhos por ano nos últimos cinco anos.

Se pensarmos em termos gerais, a grande maioria dos trabalhos foi apresentada no Intercom Jr (60), seguido pelos GPs Teorias do Jornalismo (20), Jornalismo Impresso (19), História do Jornalismo, (10), Telejornalismo (8) e, por fim, Gêneros Jornalísticos (3) Abaixo gráfico com a distribuição dos trabalhos nos GPs por ano.

Gráfico 2 - Distribuição dos trabalhos nos GT's por ano

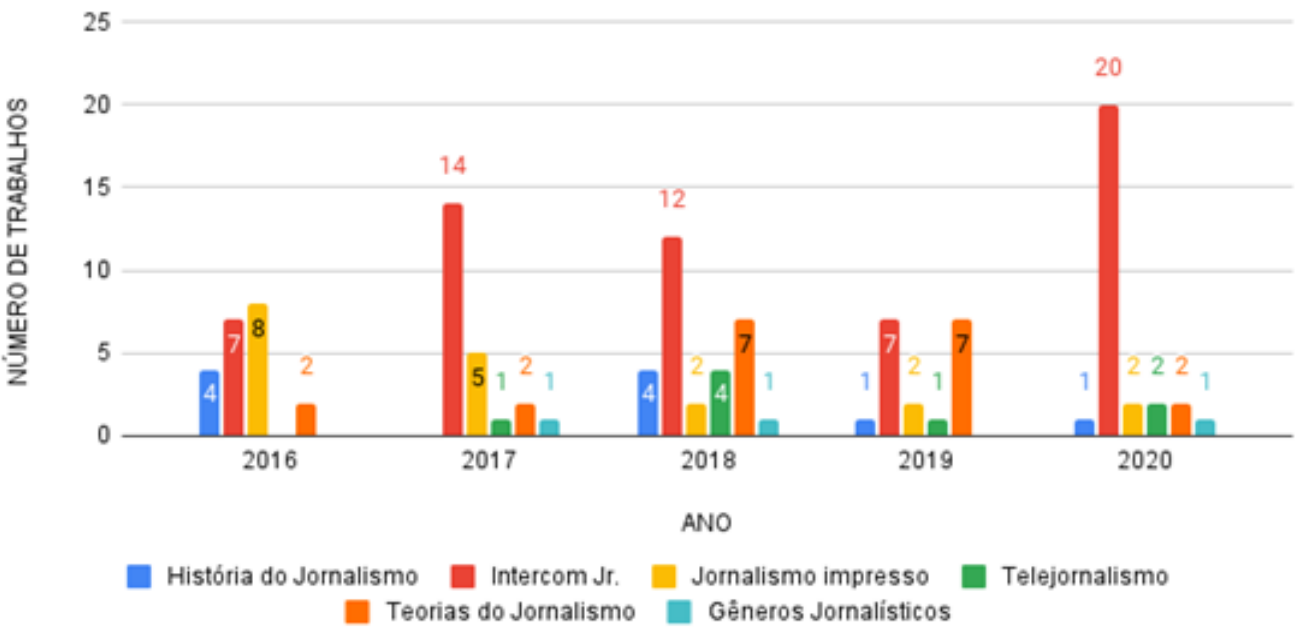

Fonte: As autoras (2021). 
Observe-se que a maior constância, além do volume, se dá no Intercom Jr, seguido do Grupo de Pesquisa Teorias do Jornalismo. O fato de o Intercom Jr concentrar 50\% dos trabalhos apresentados, por um lado é importante para sinalizar a temática como relacionada a jovens pesquisadoras(es). Por outro lado, pode ser um indicativo da baixa relação das pesquisas ${ }^{5}$ com o que estamos apontando como a não apropriação da perspectiva de gênero a partir de um horizonte teórico que realmente dê conta de operacionalizar o conceito, tornando-o uma "categoria de análise" (SCOTT, 1995). Nesse sentido, os achados coincidem com o também apontado por Tomazetti (2019) em sua ampla análise de teses e dissertações dos programas de pós-graduação na área que adotam a temática/perspectiva de gênero. Para o autor,

a ascensão dos estudos subalternos de gênero, sexualidade, feministas e queer vem acontecendo pelo caminho inverso da via tradicional dos sistemas de orientação, ele se dá pelo esforço, também por vezes isolado, solitário e autodidata, dos estudantes de pós-graduação (TOMAZETTI, 2019, p. 176).

Esta dissonância entre o interesse e as linhas de pesquisa das(os) orientadoras(es), pode estar sinalizada pelo decréscimo das pesquisas sobre gênero nos estágios seguintes, como mestrado e doutorado, ao passo em que parecem motivar muitas jovens pesquisadoras(es) nas fases iniciais de formação - graduandas(os), iniciação científica e também recém-formadas(os), por meio dos trabalhos de conclusão de curso. Por outro lado, este dado também pode indicar a falta de embasamento teórico sólido sobre a questão de gênero, no universo dos estudos em Comunicação.

Importante ressaltar que a diminuição dos trabalhos em 2019 é puxada pelo baixo índice relativo ao Intercom Jr. Naquele ano, o congresso aconteceu em Belém do Pará, o que implicou na diminuição das submissões. Inversamente, o congresso online em 2020 implicou em um aumento expressivo dos trabalhos no Intercom Jr, mas diminuição nos demais GPs.
Esses números oferecem mirada inicial sobre os trabalhos, mas para entendê-los em sua relação com o tipo de pesquisa realizada e na aproximação com o campo de estudos de gênero, é necessária uma abordagem classificatória.

Desta forma, os textos foram separados em seis categorias: 1) Representações do feminino; 2) Representações LGBTQIAP+; 3) Relações de gênero; 4) Mulheres e mercado de trabalho; 5) Jornalismo de mulheres; 6) Gênero como conceito. Essas categorias foram definidas conforme o que entendemos seja sua relação com o campo de estudos de gênero, se mais ou menos próximas das possibilidades de pesquisa dadas por este campo.

\section{Categoria 1 - Representações do feminino} (67 trabalhos de 120 - 55,8\%): a maior parte dos trabalhos se organiza a partir de uma lógica que estamos indicando como de diagnóstico da mídia. Isso significa que os estudos se propõem a analisar como as tecnologias de gênero (LAURETIS, 1994) jornalísticas constroem narrativas interligadas às representações do universo feminino, ou seja, como os suportes jornalísticos, especialmente a mídia mainstream, constroem representações acerca deste feminino. Pela sua amplitude, possui trabalhos com muitas diferenças em termos de método, suporte e objeto.

Categoria 2 - LGBTQIAP+ (16/120 - 13,3\%): uma parte significativa dos estudos investigam as representações construídas pela mídia em relação às pessoas ou temáticas LGBTQIAP+. Também aqui temos diferenças de métodos, objetos e suportes midiáticos enfocados.

Categoria 3 - Relações de gênero (8/120 6,7\%): trabalhos que tratam das representações a partir de uma perspectiva um pouco mais ampliada em relação à primeira categoria, na medida em que, por exemplo, cotejam representações de masculino e feminino, ou apropriam-se de gênero como um conceito, em certa medida, relacional.

Categoria 4 - Mulheres e mercado de trabaIho (8/120 - 6,7\%): trabalhos que relacionam as questões das mulheres ao mercado de trabalho

5 Sem desqualificar o mérito das pesquisas de graduandas(os), não se espera que estas cumpram o papel de uma construção aprofundada de matrizes teóricas e bases epistemológicas, mesmo que estas, em importantes exceções, apareçam. 
jornalístico, apontando especialmente dificuldades, preconceitos e discriminações sofridas por mulheres no exercício da profissão.

Categoria 5 - Jornalismo de mulheres (9/120 - 7,5\%): pesquisas que enfocam o jornalismo produzido por mulheres, podendo ou não ser considerado feminista. Pode referir-se a produções de mulheres especificas, partes de veículos produzidos por mulheres ou veículos integralmente relacionados à produção para mulheres e/ou feminista. Diferente da categoria anterior, o foco é o produto resultante da presença de mulheres no campo profissional.

\section{Categoria 6 - Gênero como conceito (12/120}

- 10\%): trabalhos que aproximam as questões de gênero ao jornalismo a partir de uma perspectiva conceitual. Colocam em operação premissas do campo de estudos de gênero que são cotejadas com aspectos do campo jornalístico, especialmente para propor outras formas de produção que sejam menos excludentes e assumam valores outros que não os hegemonicamente masculinistas (VEIGA DA SILVA, 2014).

Em termos de disposição das categorias no tempo, temos:

Gráfico 3 - Disposição das categorias no tempo

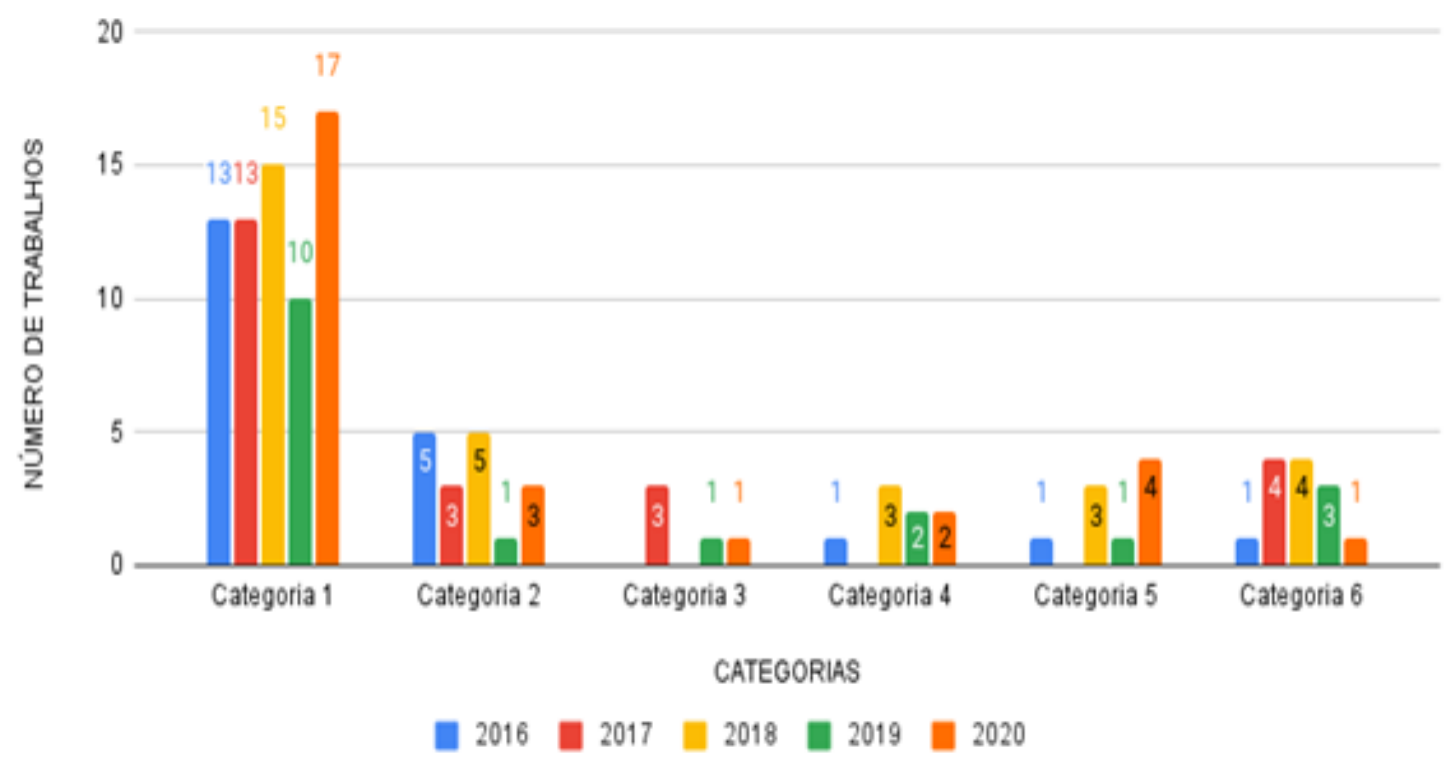

Fonte: As autoras (2021).

Como podemos observar, as três primeiras categorias (Representações do feminino, Representações LGBTQIAP+ e Relações de gênero), somadas, representam 75.7\%, da amostra. Como um todo, elas se relacionam à produção de pesquisas com diagnósticos acerca das narrativas e representações construídas pelo jornalismo em seus variados suportes e em diversos tempos.

Destas três, Representações do feminino, que reúne trabalhos que realizam diagnósticos sobre as representações de mulheres na mídia, sobressaem-se decididamente. Há trabalhos que investigam como as mulheres são retratadas do ponto de vista histórico, como em "A revista curitibana Gran-fina (1940-1942) e as regras de boa conduta feminina" (SANTOS; TEIXEIRA, 2017). Outros concentram-se na relação com a política e a representação de figuras públicas, especialmente Dilma Rousseff, como em "As expressões nervosas da presidente": estereótipos de gênero na revista IstoÉ e a repercussão com a hashtag \#IstoÉMachismo" (LOPES, 2016).

Destacamos que 17 trabalhos, quase 25\% do total daqueles agrupados nessa categoria, tratam da violência contra as mulheres e 13 usam a palavra "feminicídio", o que aponta para a importância da temática nas pesquisas. É o caso de "Feminicídio na Imprensa: Análise da Cobertura do Assassinato 
da Violonista Mayara Amaral pelas Revistas Carta Capital e Veja" (BRAGA; VENERA, 2018). Apesar do tema violência contra mulher estar presente desde 2016, com dois trabalhos por ano até 2018, em 2019 temos quatro trabalhos sobre a temática e sete em 2020. Essa ampliação, a nosso ver, indica como a discussão sobre a violência e o feminicídio passa a circular socialmente, atraindo a atenção da mídia e de pesquisadoras/es que ampliam a tendência a acompanhar estas coberturas, geralmente denunciando a dificuldade dos veículos em executar apurações adequadas do fenômeno, como em "Ética e Jornalismo em Primeiro Impacto: o discurso que tenta justificar o feminicidio" (NUNES; SENA, 2020).

A segunda categoria, Representação LGBTQIAP+, também concentra trabalhos bastantes distintos, mas é interessante observar a predominância de textos (nove entre 16) que de alguma forma referem-se a análise de coberturas sobre transgeneridades, desde o primeiro ano de nossa amostra em 2016. São trabalhos como "Quando o Jornalismo 'Faz a Egípcia': Uma Análise da Cobertura sobre Travestis no Portal das Notícias do G1" (PORTO; FEITOSA, 2016) e "Transgenia na capa da revista Vogue Paris" (PEREIRA; ANDRÉ; BASÍLIA, 2018).

Em Relações de gênero, as pesquisas colocam em diálogo o aspecto relacional dos gêneros, mesmo que de forma possivelmente pouco aprofundada, ${ }^{6}$ restringindo-se a comparações entre aspectos da cobertura, como em "Ética Jornalística: uma análise sobre os atributos das imagens do caso Neymar e Najila" (BORGES; WEBER; PAVANELLO, 2020), ou tratam gênero como um conceito central, como em "Jornalismo alternativo e abordagens de gênero: a cobertura dos direitos das mulheres e LGBT no Brasil de Fato Paraná" (RIBEIRO; WOITOWICZ, 2018).

A categoria Mulheres e mercado de trabalho engloba textos que investigam a feminilização da profissão e, como mencionamos, especialmente as dificuldades encontradas pelas mulheres no exercício do trabalho. Apresenta pesquisas que pensam as mulheres nas redações, como "Feminização do Jornalismo Goiano um Olhar Sobre as Relações de Gênero" (MORAES; TEMER, 2016) e no exercício específico, como em "A Mulher Correspondente de Guerra: Experiências de Jornalistas Brasileiras em Zonas de Conflito Bélico" (GOURLART NETTO; FURTADO, 2019). Interessante observar que de oito trabalhos, três referem-se à relação mulheres e jornalismo esportivo, como "O movimento \#DeixaElaTrabalhar e sua relação com a rotina profissional das jornalistas esportivas no Rio Grande do Sul" (STAUDT; VALIATI, 2020) talvez um dos espaços em que as interdições para corpos feminilizados seja das mais evidentes. Ao mesmo tempo, são trabalhos que apontam para a feminilização do jornalismo mesmo nos seus espaços mais tradicionalmente masculinistas, como o esporte.

Em Jornalismo de mulheres, agrupamos trabalhos que mapeiam e se referem a produções jornalistas produzidas em sua maioria por mulheres. Além de pesquisas de caráter histórico, como "Arinapi e Martha: narrativas de Maria Dimpina na revista mato-grossense A Violeta" (COSTA, 2016), e de análise da produção de mulheres em veículos contemporâneos, como "A voz feminina no jornalismo de política: análise do podcast Papo de Política" (DIAS; PATROCINIO; GUIMARÃES; MENEGUELLI, 2020) há uma presença importante, quatro textos - o que corresponde à metade do total da categoria - que se detêm na análise de produções feministas, como "Jornalismo feminino e feminista: uma análise do Portal Catarinas" (ESMITIZ; 2019).

Finalmente, a categoria Gênero como conceito busca aproximar premissas, conceitos, perspectivas do campo de estudos de gênero para ancorar discussões de caráter teórico sobre o jornalismo. Não à toa, de dez trabalhos, seis foram apresentados no GP Teorias do Jornalismo. São trabalhos que buscam pensar como produzir um outro jornalismo, diverso, "Com telas e afeto: para fazer

\footnotetext{
6 Aqui indicamos possivelmente porque não foi objeto da pesquisa a leitura integral dos textos, dado o montante do corpus. Nossas inferências, contudo, baseiam-se na qualidade da discussão proposta nos resumos avaliados, bem como na relação do conjunto dos metadados
} 
um telejornal predileto e inclusivo" (COUTINHO, 2018). Especialmente, questionam os preceitos hegemônicos da prática jornalista, a partir de outros paradigmas, como "Conhecimentos localizados no jornalismo: uma proposta de sentido de objetividade que potencialize os projetos feministas" (GUSTAFSON, 2019), ou "Saberes Plurais para o Ensino de Jornalismo: Contribuições de Mulheres para as Teorias do Jornalismo" (GONÇALVES, 2019). Interessante observar que nesta categoria aparecem dois trabalhos que pensam a questão da interseccionalidade gênero e raça.

\section{Considerações finais}

Ao realizar este mapeamento nosso objetivo era avaliar se o boom das pesquisas que preconizávamos anteriormente (MARTINEZ, LAGO E LAGO, 2016) se confirmou. E se esta possivel ampliação implicaria em uma utilização do conceito de gênero como "categoria de análise", tal qual preconizado por Scott (1995), ou seja, como capaz de alargar as operações tradicionais do que é originalmente importante no campo do jornalismo (com a ressalva que Scott se refere ao campo da história). A adoção do conceito de gênero enquanto categoria de análise, e não apenas uma outra temática específica, ou uma outra forma de se falar das pesquisas sobre mulheres, poderia consolidar a perspectiva de pensar a forma como o jornalismo está intrinsecamente relacionado aos sistemas que constroem as desigualdades - de gênero especialmente, mas também de raça e classe, para ficarmos nos três marcadores principais que podem ser chamados à cena a partir do conceito.

A opção pelo estudo da base de dados dos trabalhos apresentados no Intercom nos últimos cinco anos, nos GPs de jornalismo e no Intercom Jr referentes a jornalismo, se por um lado permite uma mirada ampla, por outro contém a limitação em vista do volume do corpus - que implica na utilização possivel dos metadados para as análises. Ao mesmo tempo, abre outras possibilidades não cobertas por este artigo, como a análise especíica de cada categoria. Ou ainda o cruzamento de autoras(es) que produziram os trabalhos, para pensar a concentração e a distribuição das temáticas regionalmente.

A pesquisa indica que os estudos de gênero no Jornalismo se mantêm como tendência, mesmo que a passos curtos. Eles aparecem atrelados especificamente a jovens pesquisadoras(es), o que indica sua centralidade para as novas gerações e, ao mesmo tempo, em termos proporcionais, a pouca aderência junto a pesquisadoras/es consolidados dentro do campo de estudos.

Por outro lado, os trabalhos ainda não se apropriam de gênero como uma categoria que permite a análise relacional e, muitas vezes, nem do vasto conhecimento já produzido no interior do campo dos estudos de gênero que não são chamados para iluminar as pesquisas em jornalismo.

Em geral, esses estudos olham para como são produzidas as representações nos suportes midiáticos, configurando o que chamamos de trabalhos de diagnóstico. Por um lado, é verdade, muitos desses trabalhos são necessários para evidenciar as formas como os produtos jornalísticos reproduzem e constroem as desigualdades de gênero e sexualidade. Por outro, contudo, o fato é que poucos avançam no sentido de relacionar as discussões teóricas do campo de estudos de gênero a modos de fazer e pensar a mídia. Como aponta Scott, ficamos ainda no aspecto da história das mulheres. Se quisermos empregar uma expressão coloquial, "no puxadinho". É como se as questões de gênero só afetassem mulheres e sua produção ou se as representações sobre mulheres e pessoas LGBTQIAP+ não estivessem intimamente relacionadas com a organização das relações sociais e de poder como um todo. Como o próprio nome sugere, os trabalhos de diagnóstico tendem a apresentar pouco alcance, uma vez que se voltam a produções específicas sem um desenho ou meta de pesquisa que dê conta de agrupar os inúmeros objetos e consiga construir uma abordagem mais ampla a partir desta junção.

Outra ausência gritante é a pouquissima presença de trabalhos que apontem para a intersecção de gênero com raça e classe. Acreditamos que gênero, raça e classe são elementos consti- 
tuintes e constitutivos do Jornalismo, tanto junto aos espaços profissionais, quanto na produção dos discursos circulantes, não sendo possivel, portanto, não os trazer para o debate.

Por fim, cumpre ressaltar que as investidas conservadoras recentes colocam em suspeição se a tendência à produção de pesquisas dentro da perspectiva de gênero se manterá. Não podemos esquecer, como já preconizava Scott, que "em nossa época, as ideologias políticas conservadoras desejariam fazer passar toda uma série de leis sobre a organização e o comportamento da família, que mudariam as práticas atuais. A conexão entre os regimes autoritários e o controle das mulheres tem sido observada..." (SCOTT, 1995, p. 90). Essas investidas, ora em curso, operam não apenas para oprimir mulheres e corpos dissidentes, mas também pesquisas que amplifiquem e deem lugar a estes corpos e suas vozes. Um paradoxo que ajuda a entender a centralidade que advogamos, mas que não se limita apenas aos estudos de gênero em relação ao jornalismo, mas a todos que procurem contemplar, dar visibilidade e voz à diversidade que constitui uma saudável experiência inclusiva e humana

\section{Referências}

ABREU, A. A. DE. Elas ocupam as redações. Rio de Janeiro: FGV, 2006.

ASSIS, C. S. DE; SOARES, R. P. DE A. Mídia, política e gênero: as mulheres políticas no noticiário. In: ASSOCIACCÃO BRASILEIRA DE PESQUISADORES EM JORNALISMO, 2011, Brasilia. Anais [...]. Brasília: SBPJor, 2011. Disponivel em: http://sbpjor.kamotini.kinghost.net/ sbpjor/resumod.php?id=1018. Acesso em: 8 jul. 2015.

BORGES, T. C.; WEBER, A.; PAVANELLO, A. Ética jornalística: uma análise sobre os atributos das imagens do caso Neymar e Najila. In: CONGRESSO BRASILEIRO DE CIÊNCIAS DA COMUNICAÇÃO, 43., 2020, São Paulo. Anais [...]. São Paulo: Intercom, 2020. Disponivel em: http://www.intercom.org.br/sis/eventos/2020/resumos/R15-0193-1.pdf. Acesso em: 28 set. 2021.

BRAGA, K. F.; VENERA, J. I. Feminicidio na imprensa: análise da cobertura do assassinato da violonista Mayara Amaral pelas Revistas Carta Capital e Veja. In: CONGRESSO BRASILEIRO DE CIÊNCIAS DA COMUNICAÇÃO, 41., 2018, Joinville. Anais [...]. São Paulo: Intercom, 2018. Disponivel em: http://www.intercom. org.br/sis/eventos/2018/resumos/R13-1312-1.pdf. Acesso em: 28 set. 2021.

COSTA, L. D. S. Arinapi e Martha: narrativas de Maria
Dimpina na revista mato-grossense A Violeta. In: CONGRESSO BRASILEIRO DE CIÊNCIAS DA COMUNICAÇÃO, 39., 2016, São Paulo. Anais [...]. São Paulo: Intercom, 2016. Disponivel em: https://portalintercom.org.br/ anais/nacional2016/resumos/R11-0252-1.pdf. Acesso em: 28 set. 2021.

COUTINHO, I. Com telas e afeto: para fazer um telejornal predileto e inclusivo. In: CONGRESSO BRASILEIRO DE CIÊNCIAS DA COMUNICAÇÃO, 41., 2018, Joinville. Anais [...]. São Paulo: Intercom, 2018. Disponivel em: https:// portalintercom.org.br/anais/nacional2018/resumos/ R13-1649-1.pdf. Acesso em: 28 set. 2021.

DIAS, D. E.; PATROCÍNIO, L. M. F.; GUIMARÃES, V. M. S.; MENEGUELLI, A. H. F. A voz feminina no jornalismo de política: análise do podcast Papo de Política. In: CONGRESSO BRASILEIRO DE CIENNCIAS DA COMUNICAÇÃO, 43., 2020, São Paulo. Anais [...]. São Paulo: Intercom, 2020. Disponivel em: http://www.intercom. org.br/sis/eventos/2020/resumos/R15-0350-1.pdf. Acesso em: 28 set. 2021.

ESCOSTEGUY. A.C.D. Midia e questões de gênero no Brasil: pesquisa, categorias e feminismos. In: ENCONTRO ANUAL DA COMPÓS, 27., 2019, Porto Alegre. Anais [...]. Porto Alegre: Compós, 2019.

ESCOSTEGUY, A. C. D.; MESSA, M. R. Os estudos de gênero na pesquisa em comunicação no Brasil. Contemporânea, Salvador, v. 4, p. 65-82, 2006.

ESMITIZ, F. Jornalismo feminino e feminista: uma análise do Portal Catarinas. In: CONGRESSO BRASILEIRO DE CIÊNCIAS DA COMUNICAÇÃO, 42., 2019, Belém. Anais [...]. São Paulo: Intercom, 2019. Disponivel em: https:// portalintercom.org.br/anais/nacional2019/resumos/ R14-1849-1.pdf. Acesso em: 28 set. 2021.

GONCALVES, G. O. Saberes plurais para o ensino de jornalismo: contribuições de mulheres para as teorias do jornalismo. In: CONGRESSO BRASILEIRO DE ClÊNCIAS DA COMUNICAÇÃO, 42., 2019, Belém. Anais [...]. São Paulo: Intercom, 2019. Disponivel em: https:// portalintercom.org.br/anais/nacional2019/resumos/ R14-0752-1.pdf. Acesso em: 28 set. 2021.

GOULART NETTO, V; FURTADO, T. H. A mulher correspondente de guerra: experiências de jornalistas brasileiras em zonas de conflito bélico. In: CONGRESSO BRASILEIRO DE CIÊNCIAS DA COMUNICAÇÃO, 42., 2019, Belém. Anais [...]. São Paulo: Intercom, 2019. Disponivel em: https://portalintercom.org.br/anais/nacional2019/ resumos/R14-2319-1.pdf. Acesso em: 28 set. 2021.

GUSTAFSON, J. Conhecimentos localizados no jornalismo: uma proposta de sentido de objetividade que potencialize os projetos feministas. In: CONGRESSO BRASILEIRO DE CIÊNCIAS DA COMUNICAÇÃO, 42., 2019, Belém. Anais [...]. São Paulo: Intercom, 2019. Disponível em: https://portalintercom.org.br/anais/nacional2019/ resumos/R14-1290-1.pdf. Acesso em: 28 set. 2021.

LAURENTIS, T. A tecnologia de Gênero. In: HOLLANDA, $H$. B. Tendências e impasse. O feminismo como critica da cultura. Rio de Janeiro: Rocco, 1994. p. 206-242.

LOPES, P. C. "As expressões nervosas da presidente": estereótipos de gênero na Revista Istoé e a repercussão com a hashtag \#IstoÉMachismo. In: CONGRESSO BRASILEIRO DE CIÊNCIAS DA COMUNICAÇÃO, 39., 
2016. São Paulo. Anais [...]. São Paulo: Intercom, 2016 Disponivel em: https://portalintercom.org.br/anais/ nacional2016/resumos/R11-0893-1.pdf. Acesso em: 28 set. 2021.

MARTINEZ, M.; HEIDEMANN, V. Relações de gênero e estudos em jornalismo: mapeamento dos trabalhos apresentados na Intercom (1977-2017). In: CONGRESSO BRASILEIRO DE CIÊNCIAS DA COMUNICAÇÃO, 41., 2018, Joinville. Anais [...]. São Paulo: Intercom, 2018. Disponivel em: https://portalintercom.org.br/anais/ nacional2018/resumos/R13-1011-1.pdf.

MARTINEZ, M.; LAGO, C.; LAGO, M. C. S. Estudos de gênero na pesquisa em jornalismo no Brasil: uma tênue relação. Famecos, Porto Alegre, v. 23, n. 2 maio/ ago. 2016.

MELO, J. M. DE; LAURINDO, R.; ASSIS, F. DE. Gêneros jornalisticos: teoria e práxis. Blumenau: Edifurb, 2012.

MORAES, A. M.; TEMER, A. C. R. P. Feminização do jornalismo goiano: um olhar sobre as relações de gênero. In: CONGRESSO BRASILEIRO DE CIÊNCIAS DA COMUNICAÇÃO, 39., 2016, São Paulo. Anais [...]. São Paulo: Intercom, 2016. Disponivel em: https://portalintercom. org.br/anais/nacional2016/resumos/R11-0855-2.pdf. Acesso em: 28 set 2021.

PERUZZO, C. M. K. Apontamentos para epistemologia e métodos na pesquisa em Comunicação no Brasil. Comunicação e Sociedade, São Paulo, v. 33, p. 25, 27 jun. 2018.

NASCIMENTO, Gênio. [Dados para pesquisa]. Destinatário: Monica Martinez. São Paulo, 15 jul. 2021. 1 mensagem eletrônica.

NUNES, M. S.; SENA, P. R. C. Ética e jornalismo em primeiro impacto: o discurso que tenta justificar o feminicídio. In: CONGRESSO BRASILEIRO DE CIÊNCIAS DA COMUNICAÇÃO, 43., 2020, São Paulo. Anais [...] São Paulo: Intercom, 2020. Disponivel em: http://www.intercom.org.br/sis/eventos/2020/resumos/R15-1011-1. pdf. Acesso em: 28 set. 2021.

PEREIRA, A. T. M.; ANDRÉ, H.; BASÍLIA, E. Transgenia na capa da revista Vogue Paris. In: CONGRESSO BRASILEIRO DE CIÊNCIAS DA COMUNICAÇÃO, 41., 2018, Joinville. Anais [...]. São Paulo: Intercom, 2018. Disponivel em: http://www.intercom.org.br/sis/eventos/2018/ resumos/R13-2349-1.pdf. Acesso em: 28 set. 2021.

PORTO, J. I. L.; FEITOSA, S. A. Quando o jornalismo "faz a egípcia": uma análise da cobertura sobre travestis no portal das notícias do G1. In: CONGRESSO BRASILEIRO DE CIÊNCIAS DA COMUNICAÇÃO, 39., 2016, São Paulo. Anais [...]. São Paulo: Intercom, 2016. Disponivel em: https://portalintercom.org.br/anais/nacional2016/ resumos/R11-2865-1.pdf. Acesso em: 28 set. 2021.

RIBEIRO, N. P.; WOITOWICZ, K. J. Jornalismo alternativo e abordagens de gênero: a cobertura dos direitos das mulheres e LGBT no Brasil de Fato Paraná. In: CONGRESSO BRASILEIRO DE CIÊNCIAS DA COMUNICAÇÃO, 41., 2018, Joinville. Anais [...]. São Paulo: Intercom, 2018. Disponivel em: http://www.intercom.org.br/sis/ eventos/2018/resumos/R13-0313-1.pdf. Acesso em: 28 set 2021.
SANTOS, J. A. H.; TEIXEIRA, N. C. R. B. Mulher e trabalho na revista Gran-Fina (1940-1942): a relação conturbada dentro da sociedade patriarcal. In: CONGRESSO BRASILEIRO DE CIÊNCIAS DA COMUNICAÇÃO, 40., 2017, Curitiba. Anais [...]. São Paulo: Intercom, 2017. São Paulo: Intercom, 2017. Disponivel em: https://portalintercom. org.br/anais/nacional2017/resumos/R12-3083-1.pdf. Acesso em: 28 set. 2021.

SCOTT, J. Gênero, uma categoria útil de análise histórica. Revista Educação e Realidade, Porto Alegre, v. 20, n. 2, p. 71-99, 1995.

STAUDT, M. R.; VALIATI, V. A. D. O movimento \#DeixaElaTrabalhar e sua relação com a rotina profissional das jornalistas esportivas no Rio Grande do Sul. In: CONGRESSO BRASILEIRO DE CIÊNCIAS DA COMUNICAÇÃO, 43., 2020, São Paulo. Anais [...]. São Paulo: Intercom, 2020. Disponivel em: http://www.intercom. org.br/sis/eventos/2020/resumos/R15-2734-1.pdf. Acesso em: 28 set. 2021.

TOMAZETTI, T. P. Genealogias dissidentes: os estudos de gênero nas teses e dissertações em comunicação do Brasil (1972-2015). 2019. 201 f. Tese (Doutorado em Comunicação e Informação) - Programa de Pós-graduação em Comunicação e Informação, Faculdade de Biblioteconomia e Comunicação, Universidade Federal do Rio Grande do Sul, Porto Alegre, 2019.

TOMAZETTI, T. P.. Por um mapa das dissidências: os estudos de gênero nas teses e dissertações em comunicação do Brasil (1972-2015). Intercom, São Paulo, v. 43, p. $57-81,2020$.

TOMAZETTI, T. P.; CORUJA, P. Relações de gênero nos estudos de recepção e consumo midiático: perspectivas de teses e dissertações em comunicação entre 2010 e 2015. Novos Olhares, São Paulo, v. 6, p. 115-128, 2017.

VEIGA DA SILVA, M. Masculino, o gênero do Jornalismo: modos de produção das notícias. Florianópolis, Insular, 2014.

\section{Monica Martinez}

Doutora em Ciências da Comunicação pela Universidade de São Paulo (USP), em São Paulo, SP, Brasil; pós-doutorado pela Universidade Metodista de São Paulo (UMESP), em São Paulo, SP, Brasil e estágio de pesquisa junto ao departamento de Rádio, Televisão e Cinema da Universidade do Texas, EUA. Docente do Programa de Pós-Graduação em Comunicação e Cultura da Universidade de Sorocaba (Uniso), em Sorocaba, SP, Brasil; colíder do Grupo de Pesquisa em Narrativas Midiáticas na mesma instituição.

\section{Claudia Lago}

Doutora em Ciências da Comunicação pela Universidade de São Paulo (USP), em São Paulo, SP, Brasil. Professora da Escola de Comunicações e Artes (ECA) no curso Licenciatura em Educomunicação, e do Programa de Pós-Graduação em Ciências da Comunicação da Universidade de São Paulo (USP), em São Paulo SP. Brasil. Presidente da Comissão de Direitos Humanos da ECA/USP 


\section{Vanessa Heidemann}

Mestra em Comunicação e Cultura pela Universidade de Sorocaba (Uniso), em Sorocaba, SP, Brasil. Integrante dos Grupos de Pesquisa Comunicação e Cultura: Narrativas Midiáticas (Uniso), em Sorocaba, SP, Brasil; Comunicação, Enunciação e Narrativas (UMESP) e Da Compreensão como Método (UMESP), em São Bernardo do Campo, SP, Brasil.

\section{Endereço para correspondência}

Monica Martinez

Universidade de Sorocaba

Programa de Pós-Graduação em Comunicação e Cultura,

$1^{\circ}$ Piso da Biblioteca Aluísio de Almeida

Cidade Universitária Professor Aldo Vannucchi

Rod. Raposo Tavares, Km 92.5

18023-000

Sorocaba, SP, Brasil

\section{Claudia Lago}

Escola de Comunicações e Artes, Universidade de São Paulo

Avenida Professor Lúcio Martins Rodrigues 443 - Prédio 1

Butantã, 05508020

São Paulo, SP, Brasil

Vanessa Heidemann

Universidade de Sorocaba

Programa de Pós-Graduação em Comunicação e Cultura

$1^{\circ}$ Piso da Biblioteca Aluísio de Almeida

Cidade Universitária Professor Aldo Vannucchi

Rod. Raposo Tavares, Km 92.5

18023-000

Sorocaba, SP, Brasil

Os textos deste artigo foram revisados pela Poá Comunicação e submetidos para validação do(s) autor(es) antes da publicação. 